\title{
PENGATURAN PELAKSANAAN DINAS JAGA DI KAPAL SESUAI STCW 1978 AS AMENDED 2010
}

\author{
Kholid Mawardi ${ }^{*}$ \\ ${ }^{1}$ Universitas Maritim AMNI, Jl. Arteri Soekarno-Hatta No. 180 Semarang \\ *Corresponding Author. E-mail: capt.jack.unimaramni@gmail.com, HP: 082256027909
}

\begin{abstract}
Abstrak
Mualim jaga memiliki peran penting dalam mengolah gerak kapal pada saat berlayar untuk menghindari hal-hal yang tidak diinginkan untuk menghindari bahaya-bahaya tubrukan. Tujuan penelitian ini adalah untuk mengetahui pengaturan pelaksanaan dinas jaga dalam mencegah terjadinya bahaya tubrukan di MT. FORTUNE GLORY XLI, optimalisasi penggunaan alat-alat navigasi untuk mencegah terjadinya bahaya tubrukan dan upaya yang dilakukan dalam kondisi darurat dinas jaga. Metode penelitian menggunakan penelitian kualitatif. Hasil penelitian adalah pelaksanaan dinas jaga di kapal yang belum terlaksana dengan benar karena Mualim jaga tidak disiplin dalam melaksanakan tugas jaga, kurangnya rasa percaya diri sebagai mualim fresh graduate pada saat melaksanakan tugas jaga di anjungan serta penggunaan alat-alat navigasi yang belum optimal. Pembagian tugas jaga di atas kapal MT. FORTUNE GLORY XLI telah sesuai dengan peraturan yang ditetapkan secara internasional tetapi dalam pelaksanaannya terdapat penyimpangan karena Mualim I sebagai senior officer tidak bertanggung jawab saat melaksanakan tugas jaganya, rasa kurang percaya diri Mualim III sebagai fresh graduate serta penggunaan alat-alat navigasi yang kurang optimal oleh para mualim menyebabkan hasil yang didapat tidak maksimal.
\end{abstract}

Kata kunci: Bahaya tubrukan, Optimalisasi dinas jaga, Navigasi

\begin{abstract}
The duty officer has an important role in managing the ship's motion while sailing to avoid things that are not desirable to avoid collision hazards. The purpose of this study was to regulate the implementation of the guard service in preventing collision hazards in MT. FORTUNE GLORY XLI, optimizing the use of navigation tools to prevent collision hazards and the efforts made in emergency conditions. The research method uses qualitative. The result of the research is that the implementation of the guard service on the ship has not been carried out correctly because the duty officer did not carry out his guard duty, did not have confidence as a new graduate officer when carrying out guard duty on the bridge and the use of navigation tools was not optimal. Division of guard duties on board the MT. FORTUNE GLORY XLI has complied with the stipulated regulations but in its implementation there are irregularities because the First Officer as a senior official is not responsible when carrying out his guard duties, the lack of confidence as a new graduate and the use of navigation tools that are less than optimal by the officers causes results what is obtained is not optimal.
\end{abstract}

Key words: Collisions' danger, optimization of guard duty, navigation. 


\section{PENDAHULUAN}

Besarnya keinginan masyarakat dewasa ini untuk menggunakan jasa angkutan laut sebagai jalur transportasi semakin bertambah, terbukti dengan meningkatnya jumlah kapal-kapal yang beroperasi secara tidak langsung akan banyak membuka lapangan kerja yang baru.

Diketahui bahwa jasa angkutan laut mempunyai resiko bahaya yang cukup tinggi, sehingga untuk mengantisipasinya diperlukan tenaga pelaut yang mengetahhui tentang dinas jaga di atas kapal dan mampu melaksanakan tugas dan tanggung jawab yang sesuai dengan ketentuan- ketentuan yang berdasarkan pada STCW 1978.

Pada tanggal 25 Juni 2010 di Manila telah disahkan Amandemen Konvensi STCW (Standart of Training, amandemen dan STCW Code). Amandemen StcW 2010 dimaksudkan untuk menyesuaikan perkembangan dan kemajuan teknologi serta tantangan baru di industri pelayaran sehingga diharapkan dapat meningkatkan keselamatan dan keamanan pelayaran internasional, transportasi laut yang lebih efisien serta perlindungan lingkungan.

Amandemen konvensi dirumuskan dengan mengedepankan prinsip good corporate governance dan social responsibility. Serta diwujudkan melalui penyeragaman kompetensi minimum dalam penerbitan sertifikat kepelautan, peningkatan pelatihan para pelaut dan penetapan kriteria kesehatan yang diimbangi dengan peningkatan pengertian kesehatan para pelaut dengan pengaturan rest hours yang memadai.

Dikarenakan banyaknya kasus tubrukan laut yang terjadi dan terbukti dari penjelasan laporan kecelakaan laut yang dipengaruhi, kompetensi atau kemampuan para kru di atas kapal adalah suatu faktor kritis dan minimnya istirahat rest hours pada $\mathrm{ABK}$ kapal sehingga mengakibatkan kurangnya konsentrasi pada saat berdinas jaga sehingga berpengaruh dalam keselamatan dan pengoperasian kapal.

Dimana kebanyakan dari mereka kurang memahami pelaksanaan dinas jaga diatas kapal sesuai dengan prosedur yang ada pada chapter VIII utamanya terkait dengan rest hour agar ABK dalam berdinas jaga tidak mengalami kehilangan konsentrasi yang mengakibatkan pada saat terjadi situasi yang membahayakan mereka sering kali terlambat atau terkesan ragu-ragu dalam mengambil suatu tindakan.

Fenomena inilah yang seringkali terjadi ketika Kapal sedang berlayar dan cenderung membawa efek yang membahayakan bagi kapal karena pengaturan pelaksanaan dinas jaga diatas kapal yang kurang efektif.

\section{KAJIAN LITERATUR}

\section{A. Pengertian Tugas Jaga Laut}

Istilah Jaga menurut kamus berarti melihat dengan cermat atau waspada. jaga juga berarti satu masa untuk berjaga. Dalam tugas jaga laut itu berarti tugas ( biasa selama empat jam) untuk perwira kapal/pekerja sebuah kapal. Jadi istilah tugas jaga berarti penjagaan dengan penuh kewaspadaan sehingga mencegah segala sesuatu yang tidak diinginkan ketika melaksanakan dinas jaga laut. 
Mematuhi semua peraturan untuk mencegah tubrukan di laut. Sebagai tambahan Perwira jaga harus memastikan bahwa pengawasan yang efisien selalu terpelihara dan sebelum melakukan tugas jaga navigasi harus memastikan bahwa keadaan sekitarnya aman untuk melakukan tugas-tugas tersebut, dan pengawasan yang efisien sedang dilakukan.

Perkembangan terakhir dalam desain kapal-kapal dagang/niaga yang lebih modern, canggih dan serba automatis menyebabkan pengurangan jumlah anggota pekerja kapal, akan tetapi juga penanganan semua administrasi kapal sehingga hal ini menyebabkan berkurangnya juga personil dalam pelaksanaan dinas jaga di kapal.

\section{B. Tujuan Dari Tugas Jaga}

Capt. E.W Manikome dalam Adi B (2012), dalam serial buku pelaut berarti melakukan penjagaan dengan cermat, awas, waspada, dengan bertujuan agar pada saat melakukan pelayaran dapat sampai di tempat tujuan dengan selamat, dan tepat waktu sesuai waktu yang telah direncanakan dengan proses pengawasan yang cermat, awas, waspada, agar tidak ada hal yang tidak diinginkan terjadi pada saat melakukan pelayaran.

Hasil penelitian pada korban akibat tubrukan di laut kandas dan sebagainya, Sering terungkap bahwa faktor penyebab utamanya adalah kegagalan untuk memelihara suatu tugas bernavigasi yang memadai dan kebugaran dan kesehatan dari perwira dek, dan ABK dek pada saat tugas jaga. Berbagai peraturan dan menyelesaikan yang disetujui oleh para wakil dari Internasional Maritime Organization (IMO-Organisasi Maritim Internasional) dimaksudkan untuk membantu para pelaut dalam memenuhi tugas-tugas jaga mereka dengan seksama. Sehingga pada saat tugas jaga semua memahami pentingnya suatu organisasi team anjungan agar tujuan dari tugas jaga dapat berjalan dengan maksimal dengan alat navigasi yang menunjang demi keselamatan pelayaran suatu kapal sebagai dasar dari penjelasan tentang tugas jaga, dalam hal ini di kutip dari konvensi Manila untuk Standard of Training Certification And Watch Keeping for Seafarers (STCW 2010) untuk setiap bab dari STCW Konvensi Manila dan kode meliputi:

1. Validasi ulang untuk petugas tingkat yang lebih tinggi dan manajerial untuk sertifikat kompetensi yang dikeluarkan oleh otoritas pemerintahan.

2. Bimbingan pelatihan yang baru dan ditingkatkannya kualitas kru kapal dan petugas yang melayani onboard.

3. Persyaratan baru MARPOL yang mencakup pelatihan kepemimpinan dan kerja sesama tim.

4. Langkah-langkah yang ketat untuk mencegah penipuan sertifikat kompetensi yang mengalir di pasar internasional.

5. Jam istirahat onboard telah ditingkatkan dari 70 jam menjadi 77 jam perminggu untuk bekerja di kapal yang layak.

6. Pengenalan petugas Electro-teknis dan sertifikat kompetensi dengan pelatihan yang telahdisetujui.

7. Fasilitas lainnya dan pelatihan yang lebih baik bagi engineer yunior dan taruna untuk mengatasi masalah kekurangan pegawai.

Sebagai dasar dari penjelasan tentang tugas jaga, dalam hal ini dikutip dari International Maritime Organization 1995 (1996) konvensi Internasional untuk

Majalah Ilmiah Bahari Jogja 89 | http://jurnal.amy.ac.id/index.php/MIBJ/ 
Standard of Training Certification And Watch Keeping for Seafarers (STCW 1978, Amandemen 1995), suatu badan internasional yang paling berwenang untuk hal ini.

Adapun kutipan-kutipan itu termasuk:

1) Basic Principles to be Observed In Keeping a Safe Navigation Watch (Prinsip-prinsip dasar yang harus dipatuhi dalam memelihara suatu tugas bernavigasi yangaman).

2) Reccomendation on Operational Guidance for Officers in Charge of Navigational Watch (rekomendasi untuk pedoman operasional bagi para perwira yang bertanggung jawab atas tugas bernavigasi)

3) Reccomendation of Principles and Operation Guidance Deck Officers in Charge of Watch in Port(Rekomendasi).

\section{Prinsip Tugas JagaLaut}

Capt. Istopo dalam buku P2TL1972 dalam aturan 2 hal ini yang harus diperhatikan yaitu:

1. Pihak-pihak yang langsung berhubungan dengan pemilik kapal, pengelola pelayaran, nahkoda dan personil jaga laut pada kegiatan berikut harus melakukan untuk menjamin bahwa jaga laut dilaksanakanselamanya.

2. Nahkoda tiap kapal terikat untuk menjamin bahwa jaga laut pengaturannya baik untuk melaksanakan jaga laut yang baik. Dibawah pengarahan umum nahkoda, maka perwira jaga bertanggung jawab terhadap navigasi kapal yang aman selama tugasnya dan tanggung jawab khususnya dalam pencegahan tubrukan dankekandasan.

3. Pengaturan jaga, meliputi :

a) Susunan jaga harus selamanya baik dan cukup untuk menanggulangi terhadap lingkungan dan kondisi harus diperhitungkan akan kebutuhan untuk melakukan pengamatan yang baik,

b) Jika menentukan susunan jaga di anjungan yang mungkin melibatkan kelasi yang baik maka harus memperhitungkan beberapa faktor diantaranya adalah kemampuan dan kecakapan dalam melaksanakan aturan dan prosedur dalam melaksanakan tugas jaga tersebut.

4. Sehat untuk melakukan tugas, meliputi: Sistem pengaturan jaga harus diatur sedemikian rupa, agar efisiensi dari perwira, ABK atau kelasi jaga tidak terganggu dengan tugas jaga yang diembannya, tugas-tugas harus diatur sedemikian rupa agar tugas jaga pertama dari awal pelayaran dan di antara petugas pengganti haruslah cukup untuk beristirahat agar tidak mengganggu tugasnya seperti tercantum pada pedoman yang berkaitan dengan tugas jaga sesuai BAB VIII SECTION B.

5. Navigasi, meliputi:

a) Semua pelayaran yang dilakukan harus direncakan sebelumnya, dan diperhitungkan semua informasi dan tiap haluan yang digariskan harus diperiksa seblum pelayaran dimulai.

b) Selama jaga, haluan yang dikemudikan, posisi dan kecepatan harus di cek dengan interval yang berkali-kali dengan baik menggunakan alat 
bantu navigasi yang diperlukan untuk meyakinkan bahwa kapal mengikuti haluan yang direncakan.

c) Perwira jaga harus menguasai sepenuhnya lokasi dan operasi semua peralatan keamanan navigasi di atas kapal dan harus diperhatikan dan diperhitungkan keterbatasan operasional dari peralatan itu.

d) Perwira yang bertugas jaga tidak boleh melakukan tugas lain yang akan mengganunggu keamanan navigasi kapal.

6. Peralatan Navigasi, meliputi:

a) Perwira jaga menggunakan semua peralatan navigasi seefektif mungkin yang berada di bawahtugasnya,

b) Jika menggunakan radar perwira jaga harus memfikirkan selama penggunaan radar harus sesuai aturan yang tercantum dalam pengaturan yang berlaku untuk mencegah trjadinya tubrukan di laut, dan

c) Jika diperlukan maka perwira jaga harus tidak ragu-ragu untuk menggunakan kemudi, mesin dan peralatan semboyan bunyi.

\section{Pelaksanakan Dinas Jaga}

International Chamber of Shipping (ICS-Kamar Dagang Pelayaran Internasional) dan laporan korban Navigasi No.15 januari 1976 menyimpulkan berbagai hasil investigasi pada tingkat Internasional yang menyatakan bahwa dua faktor berikut kelihatannya merupakan penyebab- penyebab utama tubrukan dan kapal-kapal kandas yakni, kegagalan untuk memelihara kewaspadaan yang baik dan kelemahan pada organisasi anjungan.

Sehubungan dengan kewaspadaan yang kurang baik dikarenakan beberapa faktor termasuk faktor kelelahan terkait dengan rest hours yang tercantum pada STCW chapter VIII yaitu: Nahkoda, perwira, dan anak buah kapal lainnya pada saat melaksanakan tugas jaga anjungan dan kamar mesin, atau tugas lain yang berkaitan dengan keselamatan harus berpedoman pada International Convention on Standards of Training Certification and Watchkeeping for Seafarer (STCW) 1978 yang mempersyaratkan Nahkoda dan mualim dalam menjalankan fungsi navigasi harus memiliki:

1. Pedoman yang berkaitan dengan kemampuan; pencegahan kelelahan dalam memperhatikan periode istirahat KELELAHAN (FATIGUE) Setiap orang yang akan diberikan tugasjaga sebagai mualim jaga atau Anak Buah Kapal (ABK) yang merupakan anggota jaga harus telah mendapatkan waktu istirahat sekurang- kurangnya 10 jam dalam periode 24 jam. Periode istirahat tersebut boleh terbagi tidak lebih dari dua bagian/periode, namun salah satu periodenya tidak boleh kurang dari 6 jam. Persyaratan periode istirahat diatas dapat menyimpang dalam hal emergency, atau ada suatu latihan (drill) atau dalam kondisi memaksa lainnya. Selain dari pada itu yang telah dipersyaratkan, masih dapat dikurangi, namun tidak kurang dari 6 jam dan pengurangan itu tidak boleh melebihi dya hari dalam periode 7 hari sekurangkurangnya diberikan waktu istirahat 70 jam. Untuk mencegah terjadinya kelelahan, perlu diperhatikannya persyaratan periode istirahat, pekerjaan/kegiatan yang berlebihan hanya dapat dilakukan untuk pekerjaan yang tidak dapat di tunda demi alasan keselamatan atau alasan lingkungan, atau untuk hal-hal yang tidak diantisipasi sebelumnya pada saat kapal akan

Majalah Ilmiah Bahari Jogja| 91 | http://jurnal.amy.ac.id/index.php/MIBJ/ 
memulai pelayarannya. Meskipun tidak ada definisi teknis tentangkelelahan.

2. Pedoman yang berkaitan dengan peraturan tugas jaga prinsip- prinsip yang harus diperhatikan.

3. Penanganan sumber daya dianjungan.

Penjagaan dan pengawasan yang efisien harus diterjemahkan dengan pengertian yang lengkap, termasuk pokok-pokok berikut ini:

1. Suatu kewaspadaan yang tetap atau terus menerus di seluruh penjagaan secara visual untuk memberikan gambaran yang lengkap terhadap situasi saat ini, termasuk kapal-kapal dan tanda-tanda pantai di lingkungan itu agar tetapterpelihara.

2. Keharusan untuk mengawasi perubahan-perubahan cuaca, termasuk khususnya kejelasan pandangan(visibility).

3. Keharusan untuk mengamati gerakan-gerakan dan baringan dari kapal-kapal yangmenendekat.

4. Keharusan untuk mengindentifikasi kapal dan lampu-lampu pantai dengantepat.

5. Keharusan untuk mengamati dengan radar dan pengawasan juga terhadap perum gema atau ecosounder.

6. Keharusan untuk memastikan dikendalikan dengan tepat dan perintahperintah untuk juru mudi dilakukan dengan benar.

Kelemahan pada organisasi anjungan juga merupakan kegagalan umum pada banyak peristiwa, termasuk masalah-masalah sebagai berikut:

1. Menetapkan jaga ganda pada keadaan-keadaan tertentu/keadaanramai.

2. Memastikan personil yang memadai ada pada keadaan- keadaan tertentu, contohnya lalu lintas kapal yangpadat.

3. Instruksi yang tepat untuk memanggilnakhoda.

4. Menempatkan pengawasan pada tempat-tempat yang tinggi (atasanjungan).

5. Menempatkan juru mudi yangberpengalaman.

6. Merubah dari kemudi otomatis menjadi manual/tangan (merupakan tugasrutin).

7. Instruksi yang tepat untuk mengurangi kecepatan kapal apabila menghadapi pandangan yang terbatas.

Para nakhoda dapat menerbitkan instruksi jaga yang bersifat tetap (Standing Order) yang dilengkapi dengan buku perintah malam, tapi dalam pelaksanaannya diharapkan agar para perwira jaga tidak ragu-ragu melakukan tindakan yang tepat sesuai dengan apa yang mereka lakukan.

Ada pun waktu jaga para mualim sebagai berikut:

Jam 00.00-04.00 Jaga larut malam (Dog Watch) - Mualim II. Jam 04.0008.00 jaga dini hari (Morning Watch) - Mualim I dan IV. Jam 08.00-12.00 Jam iaga pagi hari (Forenoon Watch) - Mualim III dan V Jam 12.00-16.00 Jam jaga siang hari (Afternoon Watch) - Mualim II. Jam 16.00-20.00 Jam jaga sore hari (Evening Watch) - Mualim I dan IV, Jam 20.00-24.00 Jam jaga malam hari (Night Watch) - Mualim III dan V. Kecuali diatur oleh Nakhoda, maka pelaksanaan jam jaga biasanya dilakukan seperti tertera pada daftar di atas. Perubahan jaga dilakukan dengan menyerah terimakan jaga dari perwira jaga lama ke penggantinya dan dilaksanakan $1 / 2$ jam sebelum jam pergantian jaga. 
Persiapan pada saat sebelum melaksanakan dinas jaga laut di anjungan sesuai dengan SCTW 1978 amandemen 2010 sistem jaga harus dilaksanakan sedemikian rupa sehingga efisiensi para perwira jaga tidak terhambat dan kelelahan. Tugas-tugas harus diatur agar penjagaan pertama pada perusahaan pelayaran dan istirahat jaga setelah itu secara memadai diistirahatkan dan yang sebaiknya memiliki kebugaran untuk tugas jaga berikutnya. Maksudnya yaitu jangan mendapatkan penjagaan ganda dimana setelah jaga di deck selama 4 jam sewaktu bongkar dipelabuhan jika kapal berlayar pada saat jam jaganya diistirahatkan agar merniliki kebugaran dalam tugas jaga nantinya.

Sesuai dengan Code of Federal Regulations (Kode Peraturan Federasi Amerika Serikat) Judul 46. Bagian 157.20-5(b) dan157.20- 10(a) tugas jaga tiga sistem meliputi semua perwira di daftar dan mereka harus tidak bertugas lebih dari 8 jam dalam hari, kecuali di bawah kondisi biasa.

Untuk kapal kapal dagang saat ini. Kelelahan bisa merupakan suatu masalah, terutama untuk mualim I yang bertugas jaga di atas kapal dengan tiga petugas bergiliran.Perwira jaga harus menyiapkan dirinya sendiri untuk penjagaan itu, dengan memikirkan bahwa persiapan sebelumnya yang tepat mencegah kinerja yang buruk. Ia harus mengenal rencana dan peta pelayaran yang akan digunakan selama jaga empat jam. Perwira jaga harus membaca dan menandatangani perintah-perintah jaga sebelum jaga pertamanya berada diruang peta paling tidak 20 menit sebelum jaga dan mengenal peta yang akan digunakan. Jika tugas jaga malam hari, Perwira jaga harus membaca serta menandatangani perintah malam dan memungkinkan waktu untuk penyesuaian penglihatan malam.

Pergantian jaga harus lengkap sebelum hal itu diulangi,.harus ada daftar periksa (check list) dimana para perwira yang bertugas dan menggantikan harus menandatanganinya.

Pedoman Tentang Pelaksanaan Tugas Jaga;

1. Pedoman operasional ini dibawah ini harus dipertimbangkan oleh perusahaan-perusahaan, Nahkoda dan perwira-perwira tugas jaga.

2. Pedoman khusus yang diperlukan untuk kapal kapal jenis tertentu atau untuk kapal kapal yang bermuatan berbahaya, beracun atau mudah terbakar. Nahkoda harus memberi pedoman operasional untuk hal ini sepenuhnya.

3. Perwira-perwira tugas jaga harus selalu ingat, bahwa pelaksanaan tugas secara efisien adalah perlu demi keselamatan jiwa dan harta benda di laut dan untuk mencegah pencemaran lingkungan laut.

\section{METODE PENELITIAN}

\section{A. Sumber Data}

Metode penelitian yang digunakan oleh penulis didalam menyampaikan masalah adalah deskriptif untuk menggambarkan dan menguraikan objek yang diteliti. Penelitian akan berisi kutipan-kutipan data untuk memberi gambaran penyajian laporan, data tersebut mungkin berasal dari naskah wawancara, catatan lapangan, foto, dokumen pribadi, catatan atau memo, dan dokumen resmi lainnya. Oleh karena itu di dalam pembahasan nanti penulis berusaha untuk memaparkan 
hasil dari semua studi dan penelitian yang diperoleh, baik itu secara langsung dari pengalaman penulis selama di laut dan juga penelitian dari literatur buku-buku.

1. Data Primer (Primary Data)

Data primer adalah data penelitian yang secara langsug dilakukan di atas kapal MT.FORTUNE GLORY XLI milik PT. Equator Maritime. Penelitian berlangsung selama penulis diatas kapal yang dibagi dalam tiga tahap penelitian. Tahap pertama yaitu pengenalan terhadap lingkungan kapal dan sistem kerja untuk bisa menjadi maksimal sesuai dengan aturan. Tahap kedua yaitu menganalisa kejadian dan masalah-masalah yang terjadi dikapal serta berusaha mengumpulkan data dan informasi seputar permasalahan tersebut kepada perwira serta awak kapal yang lain, baik dalam lingkup satu kapal atau dengan awak kapal yang lain.

2. Data sekunder (Secondary Data)

Data sekunder adalah data penelitian yang diperoleh secara tidak langsung atau melalui media perantara. Data sekunde dalam penelitian ini berupa buku catatan laporan maupun arsip. Selain itu penulisan menggunakan pengembangan deskriptif, artinya penulisan mencoba menggambarkan kejadian yang ada di lapangan dan hal yang dapat dilakukan di kapal MT.FORTUNE GLORY XLI dalam menyelesaikan permasalahan yang terjadi terkait pelaksanaan Dinas Jaga anjungan untuk mencegah terjadinya resiko kecelakaan kapal.

\section{B. Metode Pengumpulan Data}

Dalam penelitian ini, penulis menggunakan metode yang dapat menggambarkan tentang permasalahan yang dihadapi untuk menunjang pengoperasian kerja di MT.FORTUNE GLORY XLI. Metode pengumpulan data dengan mengadakan pengamatan secara langsung ke objek penelitian yaitu Nakhoda , Perwira Jaga dan Anak Buah Kapal(ABK) sehingga data-data yang dikumpulkan benar-benar sesuai kenyataan yang ada pada saat penelitian berlangsung. Dengan demikian akan diadakan data yang diyakini kebenarannya.

Teknik pengumpulan data yang digunakan dalam penelitian adalah sebagai berikut:

\section{Observasi}

Observasi atau pengamatan merupakan suatu tektnik atau cara mengumpulkan data dengan melakukan pengamatan langsung pada suatu kegiatan yang sedang berlangsung. Observasi diarahkan pada kegiatan memperhatikan secara akurat, mencatat fenomena yang muncul, dan mempertimbangkan hubungan antar aspek dalam fenomena tersebut. Dari pengamatan, akan mendapatkan data tentang suatu masalah, sehingga diperoleh pamahaman atau sebagai alat re-checking atau pembuktian terhadap informasi/keterangan yang diperoleh sebelumnya. (Nana Syaodih, 2013: 220). Observasi ini dilakukan oleh peneliti selama penelitian untuk mengoptimalkan data unuk menganalisis penerapan dinas jaga di kapal.

2. Wawancara interview

Wawancara adalah percakapan dengan maksud tertentu. Percakapan dilaksanakan oleh dua pihak, yaitu pewawancara (interviewer) yang mengajukan pertanyaan dan yang diwawancarai (interviewee) yang memberikan jawaban atau pertanyaan tersebut (Lexy Moloeng, 2005: 186). Teknik wawancara yang 
digunakan dalam penelitian ini adalah wawancara mendalam. Wawancara mendalam merupakan cara mengumpulkan data atau informasi dengan cara langsung bertatap muka dengan informan, dengan maksud mendapatkan gambaran lengkap tentang topik yang diteliti.

\section{Dokumentasi}

Teknik pengumpulan data dengan menggunakan dokumentasi merupakan suatu teknik pengumpulan data dengan menghimpun dan menganalisis dokumendokumen, baik tertulis, gambar, maupun elektronik. Studi dokumen merupakan pelengkap dari penggunaan metode observasi dan wawancara dalam penelitian kualitatif.

\section{Teknik Analisis Data}

Teknik analisis yang digunakan adalah teknik analisis data deskriptif, yaitu dengan cara menghimpun data-data faktual dan mendiskripsikan. Data berasal dari seluruh informasi yang diperoleh dari hasil wawancara serta dokumendokumen melalui beberapa tahap. Setelah pengumpulan data, pencatatan data, peneliti melakukan analisis interaksi yang terdiri dari reduksi data, penyajian data dan verifikasi. Analisis dari penelitian ini berlangsung bersama dengan proses pengumpulan data, maupun dilakukan setelah data data terkumpul.

1. Pengumpulan Data

Menggali informasi dan data dari berbagai sumber atau responden. yaitu dengan wawancara, observasi, analisis dokumen dan foto-foto kegiatan yang ada.

2. Reduksi Data

Dalam reduksi data, data yang diperoleh disortir karena data dari hasil wawancara merupakan data yang memiliki sifat sangat luas informasinya bahkan masih mentah. Langkah reduksi data melibatkan beberapa tahap. Tahap pertama, melakukan editing, pengelompokkan, dan meringkas data. Tahap kedua, menyusun kode-kode dan catatan-catatan mengenai berbagai hal berkaitan dengan data yang sedang diteliti sehingga peneliti dapat menentukan tematema, kelompok-kelompok, dan pola-pola data. Pada tahap terakhir dari reduksi data adalah menyusun rancangan konsep-konsep serta penjelasan-penjelasan berkenaan dengan tema, pola, atau kelompok yang bersangkutan.

3. Penyajian Data

Hasil dari pengorganisasian data yang di sajikan secara sistematis dapat dibentuk dalam sebuah laporan. Bentuk penyajian laporan berupa diskriptif analitik dan logis yang mengarah pada kesimpulan. Dalam tahap ini peneliti dituntut untuk melakukan penefsiran terhadap data dalam wawancara.

4. Penarikan Kesimpulan/Verifikasi.

Penarikan kesimpulan menyangkut intepretasi peneliti, yaitu pengembangan makna dari data yang ditampilkan. Kesimpulan yang masih kaku senantiasa di verifikasi selama penelitian berlangsung, sehingga diperoleh kesimpulan yang krediibilitas dan objektifnya terjamin. Verifikasi bisa berupa pemikiran kembali yang melintas dalam pikiran peneliti saat mengadakan pencatatan atau bisa berupa suatu tinjauan ulang terhadap catatan-catatan di lapangan.

\section{PEMBAHASAN}

Majalah Ilmiah Bahari Jogja 95 | http://jurnal.amy.ac.id/index.php/MIBJ/ 
Pada saat mengambil data di atas kapal mengenai pelaksanaan dinas jaga di MT. FORTUNE GLORY XLI ditemui kekurangan-kekurangan yang dimiliki oleh para kru dalam melaksanakan dinas jaga. Di dalam STCW 1978 Amandemen 2010 dirumuskan dengan mengedepankan prinsip good corporate gouernantce dan social responsibility serta diwujudkan melalui penyeragaman kompetensi minimum dalam penerbitan sertifikat kepelautan, Peningkatan pelatihan para pelaut dan penetapan kriteria kesehatan para pelaut dengan pengaturan rest hours yang memadai. Pengaturan waktu istirahat dimaksudkan untuk meminimalisasi penyebab human errors akibat kelelahan yang dapat membahayakan keselamatan pelayaran dan ditetapkan dengan mempertimbangkan sifat khusus kegiatan pelayaran.

Berdasarkan pada hasil pengamatan dan pengambilan data yang ada maka diambil suatu analisa yang berpatokan pada data tersebut yaitu mengenai penerapan pelaksanaan dinas jaga di atas kapal berdasarkan STCW 1978 dan perubahannya. Dengan adanya data yang didapat penulis dari hasil pengamatan/pengambilan data, maka untuk menilai efektifitas pelaksanaan dinas jaga di anjungan yang berhubungan dengan kurangnya jam istirahat ABK maka perwira/ABK seharusnya mengetahui hal apa saja yang akan dilakukan sebelum melaksanakan tugas jaga, agar pelaksanaan dinas jaga dapat lebih efektif. Dengan adanya pengetahuan dan pemahaman yang dimiliki oleh perwira/ABK maka pelaksanaan tugas jaga akan berjalan sesuai dengan aturan yang berlaku. Nahkoda, perwira, dan anak buah kapal lainnya pada saat melaksanakan tugas jaga anjungan dan kamar mesin, atau tugas lain yang berkaitan Internasional dengan keselamatan, International Convention on Standards of Training, Certification and Watchkeeping for Seafarer (STCW) 1978.

Pencegahan kelelahan dengan pengaturan peroide istirahat untuk mencegah terjadinya kelelahan pada personil yang akan melaksanakan tugas jaga, persyaratan periode istirahat tersebut dapat menyimpang dalam hal emergency, atau ada suatu latihan ( $d r i l l)$ atau dalam kondisi memaksa lainnya. Selain daripada itu yang telah dipersyaratkan di atas, dari 10 jam minimal yang dipersyaratkan, masih dapat dikurangi, namun tidak kurang dari 6 jam dan pengurangan itutidak boleh melebihi dua hari dalam periode 7 hari sekurang-kurangnya diberikan waktu istirahat 70 jam. Untuk mencegah terjadinya kelelahan, perlu diperhatikannya persyaratan periode istirahat, pekerjaan/kegiatan yang berlebihan hanya dapat dilakukan untuk pekerjaan yang tidak dapat ditunda demi alasan keselamatan atau alasan lingkungan, atau untuk hal-hal yang tidak diantisipasi sebelumnya pada saat kapal akan memulai pelayarannya. Meskipun tidak ada definisi teknis tentang kelelahan.

Berdasarkan tabel berikut dapat dianalisis sampai dimana jam istirahat yang memadai, untuk efektifitas pelaksanaan dinas jaga. Berdasarkan pada hasil pengamatan dan pengambilan data yang ada.

Tabel 1. Klasifikasi Data

\begin{tabular}{lll}
\hline \multicolumn{1}{c}{ NAMA } & JABATAN \\
\hline EKO WIDODO & ML I & \\
CHOLID BAYU ADJI & ML II & \\
\hline
\end{tabular}

Majalah Ilmiah Bahari Jogja 96 | http://jurnal.amy.ac.id/index.php/MIBJ/ 


\begin{tabular}{ll}
\hline & \\
\hline IRNA WIJAYANTI & ML III \\
CAHYO SETYABUDI & ML IV \\
AFIFAH ZAHRA NUR AINI & ML V \\
YUDHA HERMAWAN & JURU MUDI 1 \\
KHOLIS SUHERMAN & JURU MUDI 2 \\
RANGGA ADI PUTRA & JURU MUDI 3 \\
\hline
\end{tabular}

Berdasarkan pada hasil pengamatan dan pengambilan data yang ada maka penulis mengambil suatu analisa yang berpatokan pada data tersebut yaitu pelaksanaan kegiatan yang telah diuraikan diatas menunjukan bahwa setiap pelaku pelaksanaan dinas jaga mendapatkan jam istirahat yang cukup sebelum melaksanakan dinas jaga telah diuraikan setiap pelaku mendapatkan jam istirahat setidaknya minimal 11 jam perhari istirahat. Dari hasil tabel diatas yaitu:

Tabel 2. Hasil Analisa Jam Kegiatan

\begin{tabular}{|c|c|c|c|c|c|c|}
\hline Nama & Jabatan & 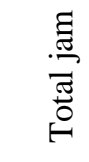 & 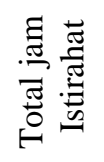 & 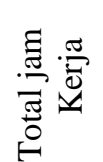 & 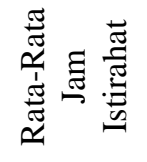 & 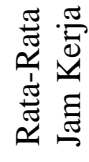 \\
\hline Eko Widodo & Mualim I & 356 & 206 & 150 & 14 & 10 \\
\hline Cholid Bayu & Mualim II & 356 & 196 & 160 & 13 & 11 \\
\hline Irna Wijayanti & Mualim III & 356 & 184 & 172 & 12 & 12 \\
\hline Cahyo S & Mualim IV & 356 & 209 & 147 & 14 & 10 \\
\hline Afifah Zahra & Mualim V & 356 & 163 & 193 & 08 & 16 \\
\hline Yudha H & Juru mudi I & 356 & 217 & 139 & 14 & 10 \\
\hline Kholis S & Juru mudi II & 356 & 209 & 147 & 14 & 10 \\
\hline Rangga A & Jurumudi III & 356 & 199 & 157 & 13 & 11 \\
\hline
\end{tabular}

Tabel 3. Pengamatan Terhadap Efektifitas Jaga Terhadap Jam Istirahat yang kurang

\begin{tabular}{|c|c|c|c|c|c|c|}
\hline \multirow{2}{*}{ 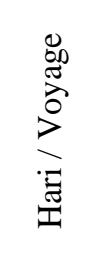 } & \multirow[b]{2}{*}{$\begin{array}{l}\underset{\Xi}{\tilde{Z}} \\
\text { Z }\end{array}$} & \multirow[b]{2}{*}{ 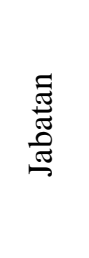 } & \multirow{2}{*}{ 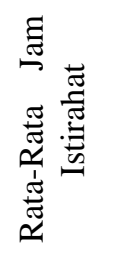 } & \multicolumn{3}{|c|}{ Pelaksanaan Dinas Jaga } \\
\hline & & & & 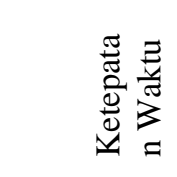 & 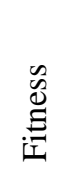 & $\begin{array}{l}\vec{\Delta} \\
\frac{0}{\pi} \\
\tilde{\omega}\end{array}$ \\
\hline 1 & 2 & 3 & 4 & 5 & 6 & 7 \\
\hline I & $\frac{\frac{8}{8}}{\frac{8}{2}}$ & $\bar{\Sigma}$ & $14 \mathrm{Jam}$ & $\sqrt{ }$ & $\sqrt{ }$ & $\sqrt{ }$ \\
\hline II & & & $14 \mathrm{Jam}$ & $\sqrt{ }$ & $\sqrt{ }$ & $\sqrt{ }$ \\
\hline III & & & $14 \mathrm{Jam}$ & $\sqrt{ }$ & $\sqrt{ }$ & $\sqrt{ }$ \\
\hline IV & & & 14 Jam & $\sqrt{ }$ & $\sqrt{ }$ & $\sqrt{ }$ \\
\hline $\mathrm{V}$ & & & $14 \mathrm{Jam}$ & $\sqrt{ }$ & $\sqrt{ }$ & $\sqrt{ }$ \\
\hline VI & & & 14 Jam & $\sqrt{ }$ & $\sqrt{ }$ & $\sqrt{ }$ \\
\hline VII & & & $14 \mathrm{Jam}$ & $\sqrt{ }$ & $\sqrt{ }$ & $\sqrt{ }$ \\
\hline VIII & & & $14 \mathrm{Jam}$ & $\sqrt{ }$ & $\sqrt{ }$ & $\sqrt{ }$ \\
\hline
\end{tabular}

Majalah Ilmiah Bahari Jogja 97 | http://jurnal.amy.ac.id/index.php/MIBJ/ 
MIBJ Vol. 19 No. 1, Februari 2021 | Kholid Mawardi

\begin{tabular}{|c|c|c|c|c|c|c|}
\hline IX & & & $14 \mathrm{Jam}$ & $\sqrt{ }$ & $\sqrt{ }$ & $\sqrt{ }$ \\
\hline $\mathrm{X}$ & & & 14 Jam & $\sqrt{ }$ & $\sqrt{ }$ & $\sqrt{ }$ \\
\hline XI & & & $14 \mathrm{Jam}$ & $\sqrt{ }$ & $\sqrt{ }$ & $\sqrt{ }$ \\
\hline XII & & & $14 \mathrm{Jam}$ & $\sqrt{ }$ & $\sqrt{ }$ & $\sqrt{ }$ \\
\hline XIII & & & 14 Jam & $\sqrt{ }$ & $\sqrt{ }$ & $\sqrt{ }$ \\
\hline XIV & & & 14 Jam & $\sqrt{ }$ & $\sqrt{ }$ & $\sqrt{ }$ \\
\hline I & 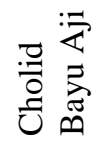 & $\begin{array}{l}\Xi \\
\Sigma\end{array}$ & $13 \mathrm{Jam}$ & $\sqrt{ }$ & $\sqrt{ }$ & $\sqrt{ }$ \\
\hline II & & & $13 \mathrm{Jam}$ & $\sqrt{ }$ & $\sqrt{ }$ & $\sqrt{ }$ \\
\hline III & & & $13 \mathrm{Jam}$ & $\sqrt{ }$ & $\sqrt{ }$ & $\sqrt{ }$ \\
\hline IV & & & $13 \mathrm{Jam}$ & $\sqrt{ }$ & $\sqrt{ }$ & $\sqrt{ }$ \\
\hline V & & & $13 \mathrm{Jam}$ & $\sqrt{ }$ & $\sqrt{ }$ & $\sqrt{ }$ \\
\hline VI & & & $13 \mathrm{Jam}$ & $\sqrt{ }$ & $\sqrt{ }$ & $\sqrt{ }$ \\
\hline VII & & & 13 Jam & $\sqrt{ }$ & $\sqrt{ }$ & $\sqrt{ }$ \\
\hline VIII & & & $13 \mathrm{Jam}$ & $\sqrt{ }$ & $\sqrt{ }$ & $\sqrt{ }$ \\
\hline IX & & & $13 \mathrm{Jam}$ & $\sqrt{ }$ & $\sqrt{ }$ & $\sqrt{ }$ \\
\hline $\mathrm{X}$ & & & $13 \mathrm{Jam}$ & $\sqrt{ }$ & $\sqrt{ }$ & $\sqrt{ }$ \\
\hline XI & & & $13 \mathrm{Jam}$ & $\sqrt{ }$ & $\sqrt{ }$ & $\sqrt{ }$ \\
\hline XII & & & $13 \mathrm{Jam}$ & $\sqrt{ }$ & $\sqrt{ }$ & $\sqrt{ }$ \\
\hline XIII & & & $13 \mathrm{Jam}$ & $\sqrt{ }$ & $\sqrt{ }$ & $\sqrt{ }$ \\
\hline XIV & & & $13 \mathrm{Jam}$ & $\sqrt{ }$ & $\sqrt{ }$ & $\sqrt{ }$ \\
\hline I & $\begin{array}{l}3 . \\
\stackrel{\Xi}{\Xi}\end{array}$ & $\begin{array}{l}\text { 列 } \\
\bar{\Sigma}\end{array}$ & $12 \mathrm{Jam}$ & $\sqrt{ }$ & $\sqrt{ }$ & $\sqrt{ }$ \\
\hline II & & & 12 Jam & $\sqrt{ }$ & $\sqrt{ }$ & $\sqrt{ }$ \\
\hline III & & & $12 \mathrm{Jam}$ & $\sqrt{ }$ & $\sqrt{ }$ & $\sqrt{ }$ \\
\hline IV & & & $12 \mathrm{Jam}$ & $\sqrt{ }$ & $\sqrt{ }$ & $\sqrt{ }$ \\
\hline $\mathrm{V}$ & & & $12 \mathrm{Jam}$ & $\sqrt{ }$ & $\sqrt{ }$ & $\sqrt{ }$ \\
\hline VI & & & $12 \mathrm{Jam}$ & $\sqrt{ }$ & $\sqrt{ }$ & $\sqrt{ }$ \\
\hline VII & & & $12 \mathrm{Jam}$ & $\sqrt{ }$ & $\sqrt{ }$ & $\sqrt{ }$ \\
\hline VIII & & & $12 \mathrm{Jam}$ & $\sqrt{ }$ & $\sqrt{ }$ & $\sqrt{ }$ \\
\hline IX & & & 12 Jam & $\sqrt{ }$ & $\sqrt{ }$ & $\sqrt{ }$ \\
\hline$X$ & & & $12 \mathrm{Jam}$ & $\sqrt{ }$ & $\sqrt{ }$ & $\sqrt{ }$ \\
\hline XI & & & $12 \mathrm{Jam}$ & $\sqrt{ }$ & $\sqrt{ }$ & $\sqrt{ }$ \\
\hline XII & & & $12 \mathrm{Jam}$ & $\sqrt{ }$ & $\sqrt{ }$ & $\sqrt{ }$ \\
\hline XIII & & & $12 \mathrm{Jam}$ & $\sqrt{ }$ & $\sqrt{ }$ & $\sqrt{ }$ \\
\hline XIV & & & $12 \mathrm{Jam}$ & $\sqrt{ }$ & $\sqrt{ }$ & $\sqrt{ }$ \\
\hline I & 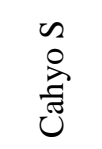 & $\begin{array}{l}z \\
\Sigma\end{array}$ & 14 Jam & $\sqrt{ }$ & $\sqrt{ }$ & $\sqrt{ }$ \\
\hline II & & & 14 Jam & $\sqrt{ }$ & $\sqrt{ }$ & $\sqrt{ }$ \\
\hline III & & & 14 Jam & $\sqrt{ }$ & $\sqrt{ }$ & $\sqrt{ }$ \\
\hline IV & & & 14 Jam & $\sqrt{ }$ & $\sqrt{ }$ & $\sqrt{ }$ \\
\hline $\mathrm{V}$ & & & 14 Jam & $\sqrt{ }$ & $\sqrt{ }$ & $\sqrt{ }$ \\
\hline VI & & & 14 Jam & $\sqrt{ }$ & $\sqrt{ }$ & $\sqrt{ }$ \\
\hline VII & & & $14 \mathrm{Jam}$ & $\sqrt{ }$ & $\sqrt{ }$ & $\sqrt{ }$ \\
\hline VIII & & & $14 \mathrm{Jam}$ & $\sqrt{ }$ & $\sqrt{ }$ & $\sqrt{ }$ \\
\hline IX & & & 14 Jam & $\sqrt{ }$ & $\sqrt{ }$ & $\sqrt{ }$ \\
\hline$X$ & & & $14 \mathrm{Jam}$ & $\sqrt{ }$ & $\sqrt{ }$ & $\sqrt{ }$ \\
\hline XI & & & 14 Jam & $\sqrt{ }$ & $\sqrt{ }$ & $\sqrt{ }$ \\
\hline XII & & & 14 Jam & $\sqrt{ }$ & $\sqrt{ }$ & $\sqrt{ }$ \\
\hline XIII & & & 14 Jam & $\sqrt{ }$ & $\sqrt{ }$ & $\sqrt{ }$ \\
\hline
\end{tabular}

Majalah Ilmiah Bahari Jogja 98 | http://jurnal.amy.ac.id/index.php/MIBJ/ 


\begin{tabular}{|c|c|c|c|c|c|c|}
\hline XIV & & & $14 \mathrm{Jam}$ & $\sqrt{ }$ & $\sqrt{ }$ & $\sqrt{ }$ \\
\hline I & $\begin{array}{l}N \\
\text { 霖 } \\
\text { 这 }\end{array}$ & $\vec{z}$ & $8 \mathrm{Jam}$ & $\sqrt{ }$ & $\sqrt{ }$ & $\sqrt{ }$ \\
\hline II & & & $8 \mathrm{Jam}$ & $\sqrt{ }$ & - & $\sqrt{ }$ \\
\hline III & & & $8 \mathrm{Jam}$ & $\sqrt{ }$ & - & $\sqrt{ }$ \\
\hline IV & & & $8 \mathrm{Jam}$ & - & - & $\sqrt{ }$ \\
\hline V & & & $8 \mathrm{Jam}$ & - & - & $\sqrt{ }$ \\
\hline VI & & & $8 \mathrm{Jam}$ & - & - & $\sqrt{ }$ \\
\hline VII & & & $8 \mathrm{Jam}$ & - & - & $\sqrt{ }$ \\
\hline VIII & & & $8 \mathrm{Jam}$ & - & - & $\sqrt{ }$ \\
\hline IX & & & $8 \mathrm{Jam}$ & - & - & $\sqrt{ }$ \\
\hline $\mathrm{X}$ & & & $8 \mathrm{Jam}$ & - & - & $\sqrt{ }$ \\
\hline XI & & & $8 \mathrm{Jam}$ & - & - & $\sqrt{ }$ \\
\hline XII & & & $8 \mathrm{Jam}$ & - & - & $\sqrt{ }$ \\
\hline XIII & & & $8 \mathrm{Jam}$ & $\sqrt{ }$ & $\sqrt{ }$ & $\sqrt{ }$ \\
\hline XIV & & & $8 \mathrm{Jam}$ & $\sqrt{ }$ & $\sqrt{ }$ & $\sqrt{ }$ \\
\hline I & $\begin{array}{l}\frac{\pi}{\sigma} \\
\bar{\sigma}\end{array}$ & 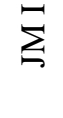 & $14 \mathrm{Jam}$ & $\sqrt{ }$ & $\sqrt{ }$ & $\sqrt{ }$ \\
\hline II & & & 14 Jam & $\sqrt{ }$ & $\sqrt{ }$ & $\sqrt{ }$ \\
\hline III & & & 14 Jam & $\sqrt{ }$ & $\sqrt{ }$ & $\sqrt{ }$ \\
\hline IV & & & $14 \mathrm{Jam}$ & $\sqrt{ }$ & $\sqrt{ }$ & $\sqrt{ }$ \\
\hline V & & & 14 Jam & $\sqrt{ }$ & $\sqrt{ }$ & $\sqrt{ }$ \\
\hline VI & & & $14 \mathrm{Jam}$ & $\sqrt{ }$ & $\sqrt{ }$ & $\sqrt{ }$ \\
\hline VII & & & 14 Jam & $\sqrt{ }$ & $\sqrt{ }$ & $\sqrt{ }$ \\
\hline VIII & & & 14 Jam & $\sqrt{ }$ & $\sqrt{ }$ & $\sqrt{ }$ \\
\hline IX & & & 14 Jam & $\sqrt{ }$ & $\sqrt{ }$ & $\sqrt{ }$ \\
\hline$X$ & & & $14 \mathrm{Jam}$ & $\sqrt{ }$ & $\sqrt{ }$ & $\sqrt{ }$ \\
\hline XI & & & 14 Jam & $\sqrt{ }$ & $\sqrt{ }$ & $\sqrt{ }$ \\
\hline XII & & & $14 \mathrm{Jam}$ & $\sqrt{ }$ & $\sqrt{ }$ & $\sqrt{ }$ \\
\hline XIII & & & $14 \mathrm{Jam}$ & $\sqrt{ }$ & $\sqrt{ }$ & $\sqrt{ }$ \\
\hline XIV & & & $14 \mathrm{Jam}$ & $\sqrt{ }$ & $\sqrt{ }$ & $\sqrt{ }$ \\
\hline
\end{tabular}

Setelah melihat tabel di atas yang menunjukan bahwa mualim V mendapatkan jam istirahat yang kurang sehingga pada saat melaksanakan dinas jaga kurang efektif sehubungan dengan keterlambatan pada saat pelaksanaan dinas jaga, sehingga dapat disimpulkan bahwa mualim $\mathrm{V}$ kurang sehat dalam pelaksaanan dinas jaga atau dapat dikatakan Fatique dan tidak memenuhi standar stcw 1978 dan perubahannya.

Untuk mengurangi terjadi kecelakaan kapal di laut dikarenakan human errors. Salah satu permasalahan yang dibahas dalam STCW 1978 Amandemen 2010 adalah peningkatan jam istirahat dari 70 jam menjadi 77 jam perminggu. Maksud dari peningkatan jam istirahat ini adalah untuk mengurangi penyebab human erorrs akibat kelelahan yang mengakaibatkan kurangnya keselamatan pelayaran.

Konvensi STCW juga mencakup pengaturan Watchkeeping.Ini termasuk waktu istirahat minimal pelaut untuk mencegah kelelahan dan dipastikan bahwa pelaut cocok untuk bertugas jaga. STCW yang jam istirahat minimal sekarang diselaraskan dengan jam kerja persyaratan diadopsi oleh Organisasi Perburuhan 
Internasional termasuk ILO Konvensi Buruh Maritim (MLC). Persyaratan baru istirahat jam IMO akan diberlakukan di Januari 2012 dan memperkenalkan persyaratan minimum ketat dari yang saat ini berlaku.

\section{Kebugaran Untuk Bertugas}

Kebugaran untuk bertugas adalah sebagaian hal yang sangat penting demi menunjangnya keselamatan pelayaran untuk mencapai efektifitas atau efesiensi dalam melaksanakan perjalanan hingga sampai di tempat tujuan maka diuraikan pembahasan di bawah ini. Istirahat yang besar membawa pemulihan, dan penambahan kekuatan setelah digunakan.Tidur merupakan faktor penting dalam istirahat, dimana selama tidur semua fungsi-fungsi tubuh terisi diperbaharui lagi. Istirahat tidak hanya mercakup tidur, tetapi juga bersantai, perubahan dalam aktifitas, menghilangkan segala tekanan-tekanan kerja atau maasalah-masalah lainnya. Pikiran, semuanya dapat menenangkan otot-otot. Kegiatan-kegiatan yang dilakukan oleh seseorang pada saat ini sangat melelahkan, umat manusia berjuang/berusaha keras untuk bekerja.Kita semua membutuhkan istirahat untuk melawan segala kepenatan.

Sesuai dengan peraturan maka sistem penjagaan harus sedemikian rupa sehingga efisiensi para perwira jaga dan pelaut-pelaut jaga deck (Deck Rating) dan jaga mesin tidak terganggu karena kelelahan. Tugas-tugas harus diatur sedemikian rupa agar tugas jaga pertama pada permulaan suatu pelayaran (voyage) dan pengantian tugas-tugas berikutnya diberi istirahat yang cukup dan yang sebaliknya sehingga tetap bugar untuk bertugas. Supaya tetap bugar maka harus diperhatikan peraturan kesehatan dan keselamatan.kerja. Memaksimumkan jam kerja rata- rata tidak lebih 12 jam perhari, setiap perwira dan rating yang akan di beri tugas jaga harus minimal 10 jam istrahat dalam periode 24 jam. Jumlah jam istrahat boleh dibagi tidak lebih dari periode yang salah satu periodenya paling lama 6 jam lamanya. Pengecualian dari kondisi butir satu dan dua di atas, sepuluh jam minimal istrahat untuk periode 7 hari.

Kecelakaan dengan segala bentuk dan akibatnya dapat merugikan pengusaha dan masyarakat karena kecelakaan akan menimbulkan penderitaan lahir dan batin atau kerugian yang bersifat ekonomis. Sebaliknya dengan terselenggaranya kegairahan kerja yang menunjang pertumbuhan dan perkembangan produksi dan produktivitas serta memberikan iklim yang baik dalam menimbulkan stabilitas sosial terutama di kalangan masyarakat ketenaga kerjaan.

Dari uraian di atas dapat simpulkan bahwa masalah bersama adalah, sehubungan dengan efektifitas jam istirahat yang kurang sehingga sangat berpengaruh terhadap kesehatan kerja dan utamanya pada keselamatan kerja, sangat pentingnya pemberhatian terhadap jam-jam istirahat kepada semua kru khususnya pada pelaku pelaksana dinas jaga di anjungan untuk menjamin keselamatan kerja dan keselamatan selama pelayaran berlangsung.

Adapun yang perlu diperhatikan agar mencegah terjadinya minimnya jam istirahat atau rest period, adalah dokumentasi waktu istirahat harian harus terpelihara dengan baik dan ditandatangani oleh nahkoda, atau perwira yang ditunjuk oleh nahkoda. Salinan dari catatan jam istirahat dan jadwal berkenaan kru kapal, yang sepatutnya disahkan oleh nahkoda atau perwira yang diberi 
kewenangan oleh nahkoda, harus diberikan juga kepada crew yang bersangkutan, agar terpeliharanya jam istirahat yang baik sesuai dengan standar stcw 1978 chapter VIII bagian B.

\section{Berikut Pedoman Pencegahan Kelelahan Yang Berkaitan Dengan Tugas Jaga.}

Minimum jumlah istirahat dalam jangka waktu 7 hari meningkat menjadi 77 jam dari 70 jam. Pelaut harus selalu memiliki 10 jam istirahat dalam 24 jam periode tanpa pengecualian, kecuali dalam keadaan darurat; Sekarang wajib untuk mempertahankan catatan setiap individu pelaut jam istirahat, yang mungkin diperiksa selama Pelabuhan Kontrol Negara inspeksi.

Sisanya batas jam sekarang berlaku untuk kebanyakan pelaut di kapal, termasuk master, tidak hanya watchkeepers seperti yang sebelumnya telah terjadi. Dari Januari 2012, pelaut akan perlu untuk meninjau dan menandatangani catatan kerja/istirahat mereka jam periodik (biasanya minimal sebulan sekali) untuk memastikan mereka mematuhi sisa minimal jam ditetapkan.

Meskipun untuk "kelelahan" tidak ada definisi yang seragam, tetapi setiap orang yang terlibat didalam pengoperasian kapal harus selalu waspada terhadap faktor-faktor yang dapat menyebabkan terjadinya kelelahan tersebut termasuk (tetapi tidak terbatas pada) faktor-faktor yang disebabkan oleh organisasi, yang harus dipertimbangkan jika membuat keputusan-keputusan yang berkaitan dengan pengoperasian kapal.

Dalam menerapkan Peraturan VIII, hal-hal berikut harus diperhatikan: Ketentuan-ketentuan yang dibuat untuk mencegah kelelahan, harus menjanin bahwa jam kerja yang berlebihan atau tidak masuk akal, tidak akan diterapkan. Periode-periode istirahat minimum yang ditetapkan didalam Section A-VIII/I secara khusus, tidak boleh diartikan bahwa jam-jam kerja yang selebihnya dapat dicurahkan pada tugas jaga atau tugas-tugas lain.

Frekuensi dan lama periode istirahat, serta pemberian waktu istirahat tambahan sebagai kompensasi adalah merupakan faktor-faktor materi yang mencegah terjadinya kelelahan. Ketentuan dalam hal ini bervariasi untuk kapalkapal yang melakukan pelayaran-pelayaran pendek, asalkan pengaturan keselamatan tetap diterapkan. Pemerintah harus mempertimbangkan penerapan suatu persyaratan yang mencatat jam-jam kerja dan jam- jam istirahat bagi para pelaut dan catatan-catatan semacam ini harus diperiksa oleh pemerintah yang bersangkutan secara berskala, untuk menjamin telah dijalankan terhadap peraturan yang terkait sesuai dengan aturan stcw 1978 chapter VIII.

Berdasar pada informasi yang diperoleh oleh penyelidikan kecelakaan kecelakaan laut. Pemerintah harus selalu meninjau untuk ketentuan-ketentuan yang diberlakukannya sendiri yang sehubungan dengan pencegahan kelelahan.

\section{PENUTUP}

\section{Kesimpulan}

Berdasarkan pada pembahasan masalah dapat disimpulkan bahwa:

1. Pelaksanaan dinas jaga diatas kapal MT. FORTUNE GLORY XLI tidak terlaksana secara optimal. 
2. Kegiatan dinas jaga diatas kapal MT. FORTUNE GLORY XLI tidak mengimplementasikan STCW 1978 dan perubahannya.

\section{Saran-Saran}

Adapun saran yang dapat dikemukakan antara lain adalah sebagai berikut:

1. Harus dilakukan safety meeting di atas kapal, hal ini dimaksudkan untuk membahas mengenai apa yang seharusya perwira jaga lakukan dan yang tidak boleh dilakukan dalam pelaksanaan dinas jaga, sehingga pelakasaan dinas jaga dapat berjalan secara optimal sehubungan jamistirahat.

2. Diharapkan kepada pihak perusahaan untuk melakukan sosialisasi ataupun pengadaan buku pedoman STCW 1978 dan Perubahannya ini diatas kapal MT. FORTUNE GLORY XLI, agar para perwira jaga dapat memahami apa sebenarnya isi dari STCW 1978 dan Perubahannya tersebut dan kemudian nantinya dapat diterapkan dalam pelaksanaan dinas jaga diatas kapal.

\section{DAFTAR PUSTAKA}

Adi B, L. (2012). Watch Keeping Oleh Capt. E W Manikome.

Badan Diklat Perhubungan. 2000, Basic Safety Training (BST) Modul - 4. Jakarta.

Basic safety training, "Personal safety and social responsibility emergency procedure", PLAP, Jakarta

Hakim, A. R., Wibowo, W., Astriawati, N., Prodi, A., Kapal, P., Tinggi, S., ... Maritim, T. (2020). SISTEM PENDINGIN MESIN DIESEL PADA WHELL LOADER KOMATSU WA120-3CS. Teknovasi, Jurnal, 07, 76-85.

Hobbystar H, Parlin. Analisis Penerapan Collision Regulation 1972 Terhadap Keselamatan Pelayaran Kapal Milik PT Serunting Sriwijaya Palembang Tahun 2007. http://expressclass.blogspot.com/2009/02/analisis-penerapancollision-regulation.html

International Maritime Organization 1995. STCW Convention with Resolution of 1995 Conferance and Subsequence Amandement to the Convention Code. , (1996).

Leonard Adi bestari (2012), Watch Keeping Oleh Capt. E W Manikome, https://leonardadibestari.blogspot.com/2012/10/tugas-jaga.html (06 Oktober 2012)

Moreby D H. Manajemen Kepegawaian Kapal-kapal Niaga, http://opac.pipsemarang.ac.id/index.php?p=show_detail\&id=2158\&keywords $=$

Undang-undang Republik Indonesia Nomor 17 Tahun 2008 tentang Pelayaran.

Perwira Pelayaran Niaga (2019), Manajemen Kapal, https://perwirapelayaranniaga.com/manajemen-perkapalan/ (20 desember 2019)

Malisan, Johny. Analisis Kecenderungan Kecelakaan Kapal di Indonesia. Dalam Warta Penelitian Perhubungan. 2009. Jakarta: Badan Litbang Perhubungan. 
Purjiyono, Ningrum Astriawati, P. S. s. (2019). Perawatan Sistem Pelumasan Mesin Utama Pada Kapal Km. Mutiara Sentosa Ii. Teknovasi, 06, 74-80.

Ridwan. Metode dan Teknik Menyusun Proposal Penelitian. 2009. Bandung : Penerbit Alfabeta. 